\title{
Parental satisfaction with communication provided by different health care personnel at Lady Ridgeway Hospital for Children, Colombo
}

\author{
R R C Fernando ${ }^{1}$, M P Senanayake ${ }^{2}$ \\ Sri Lanka Journal of Child Health, 2012; 41(4): 180-185
}

\begin{abstract}
Objective: To evaluate parental satisfaction with communication provided by health care personnel at Lady Ridgeway Hospital and to determine if differences existed in selected groups.
\end{abstract}

Study design: A prospective descriptive crosssectional study.

Study setting: All six medical wards of Lady Ridgeway Hospital for Children, Colombo

Study population: Patients aged 6 months to 14 years with a single hospitalization for a period of five or more days or with two or more hospitalization episodes for the same illness were serially enrolled until the calculated sample size of 458 were recruited.

Method: Parental satisfaction with communication provided by doctors, nurses $\&$ physiotherapists was evaluated using a pretested questionnaire. Demographic details and parental knowledge about child's illness were recorded by an interviewer not involved in the care of the child. Richards Scale (a five point scoring system) assessed parental satisfaction regarding 'establishing rapport', 'health advice received', 'caring attitude towards patient' \& 'moral support provided'.

Results: Of 458 parents interviewed 95\% were mothers. All received care from doctors and nurses but only 49 had met physiotherapists. Forty-one (9\%) had more than 5 admissions for chronic illnesses, $53 \%$ were first admissions and 38\% recurrent admissions. Hospital stay ranged from 5 to 21 days. Mean age of patients was 4.5 years. Male: female ratio was 3:2. Type of illnesses ranged from acute infections to chronic illness and disabilities. Majority of respondents were educated up to GCE O/L and $8 \%$ were graduates. Doctors were rated highest for their

\footnotetext{
${ }^{1}$ Senior Registrar in Paediatrics, Lady Ridgeway Hospital, Colombo, ${ }^{2}$ Professor in Paediatrics, Faculty of Medicine, Colombo
}

(Received on 20 December 2011: Accepted on 27 January 2012) ability to establish rapport at initial encounter, and lowest for their ability to inform parents of prognosis and follow-up management plans. Time taken by doctors for questions of parents and advice given about the illness were also considered inadequate. There was overall satisfaction regarding a caring attitude by all three categories of personnel but physiotherapists were rated best in this aspect, doctors next and nurses the lowest. There was no significant variation in the demographic variables of ethnicity or gender and communication received. Parental knowledge on illness on the day of discharge was better in recurrent admissions although there was no significance (Mean score in first admissions 24.32, recurrent admissions 25.21).

Conclusion: There was overall satisfaction among parents at LRH but we found several aspects of communication that need improvement for delivery of better quality in-door care.

(Key words: Parental satisfaction; communication; health care personnel; Lady Ridgeway Hospital for Children)

\section{Introduction}

Patient-provider communication in the health sector in Sri Lanka has been receiving increasing interest with gaps in communication being highlighted by health authorities and mass media. With quantitative parameters of child health in Sri Lanka being comparable to those in developed countries, the present need is to improve the quality of health care $^{1,2}$. Medical school curricula and postgraduate examinations are focusing more and more on communication skills of medical and other health care givers, but studies on the quality of communication in health care settings have been $\mathrm{few}^{3}$. In paediatric practice communication is mostly between the health provider and parents and therefore parents are the best group from a consumers' perspective to evaluate communication aspects of child health delivery services. We investigated the perception of parents on communication skills of different health care personnel at the premier children's hospital in Sri Lanka. 


\section{Objectives}

To evaluate parental satisfaction on communication provided by different categories of health care providers in a hospital setting and to correlate patient variables with parental satisfaction.

\section{Study design}

A prospective, descriptive, cross sectional study

\section{Study setting}

All six paediatric medical wards at Lady Ridgeway Hospital for Children (LRH), Colombo

\section{Study population}

All patients aged 6 months to 14 years with a single hospitalization for a period of five or more days or with two or more hospitalization episodes for the same illness, were serially enrolled from $1^{\text {st }}$ March to $31^{\text {st }}$ May 2010 until the calculated sample size of 458 was recruited. Children without an accompanying parent were excluded.

\section{Method}

Data was gathered on the day of discharge from hospital by an interviewer who visited the six medical wards on a daily basis during the study period. The interviewer was not involved in the care of the children in any way. A pretested questionnaire, which focused on demographic details and parental satisfaction on verbal communication provided by three categories of health care personnel (doctors, nurses \& physiotherapists), was used to gather information. At the end of the interview overall parental knowledge about the child's illness was also assessed. Consent from consultants in charge of the study population and ethical clearance from the Ethics Committee of the Lady Ridgeway Hospital for Children were obtained prior to the commencement of the study. Informed consent was obtained from each responding parent.
Richards scale, a five point scoring system utilized in qualitative studies, assessed parental satisfaction on : 'establishing initial rapport', 'health advice received', 'overall attitude to patient and care-giving', 'psychological / moral support provided' and for evaluating parental knowledge on child's illness. Scores awarded were 10 for excellent, 8 for very good, 6 for good, 4 for poor and 2 for very poor. Data was analyzed using SPSS.17 software.

\section{Results}

A total of 458 parents was interviewed which included 243 (53\%) first admissions and 215 (47\%) repeat / recurrent admissions; forty one (9\%) had more than five admissions for chronic illnesses. Reasons for hospitalization ranged from acute infections to chronic illnesses like epilepsy, bronchial asthma and motor disabilities. Duration of stay ranged from 5 to 21 days. All subjects received care from doctors and nurses but only 49 met physiotherapists.

The demographic characteristics of the patients and respondents are shown in table 1.

Mean age of the patient population was 4.5 years. Male to female ratio was 3:2. All major ethnic groups in the country were represented: Sinhala 355 (78\%), Tamil 57 (12\%) and Muslim 46 (10\%). Three hundred and seventy seven (82.3\%) spoke Sinhala only, $70(15.3 \%)$ spoke both Tamil and Sinhala while $11(2.4 \%)$ spoke only Tamil (Table 1$)$.

Mothers were the respondents in 450 (95\%) interviews. All respondents were literate, over a third of parents (38.9\% of mothers and $37.1 \%$ of fathers) were educated up to $\mathrm{O} / \mathrm{Level}$ and $4 \%$ of mothers held university degrees. Monthly family income was above Rs. 10, 000 in 346 (75\%) families (Table 1). 
Table 1: Demographic characteristics of patients and respondents

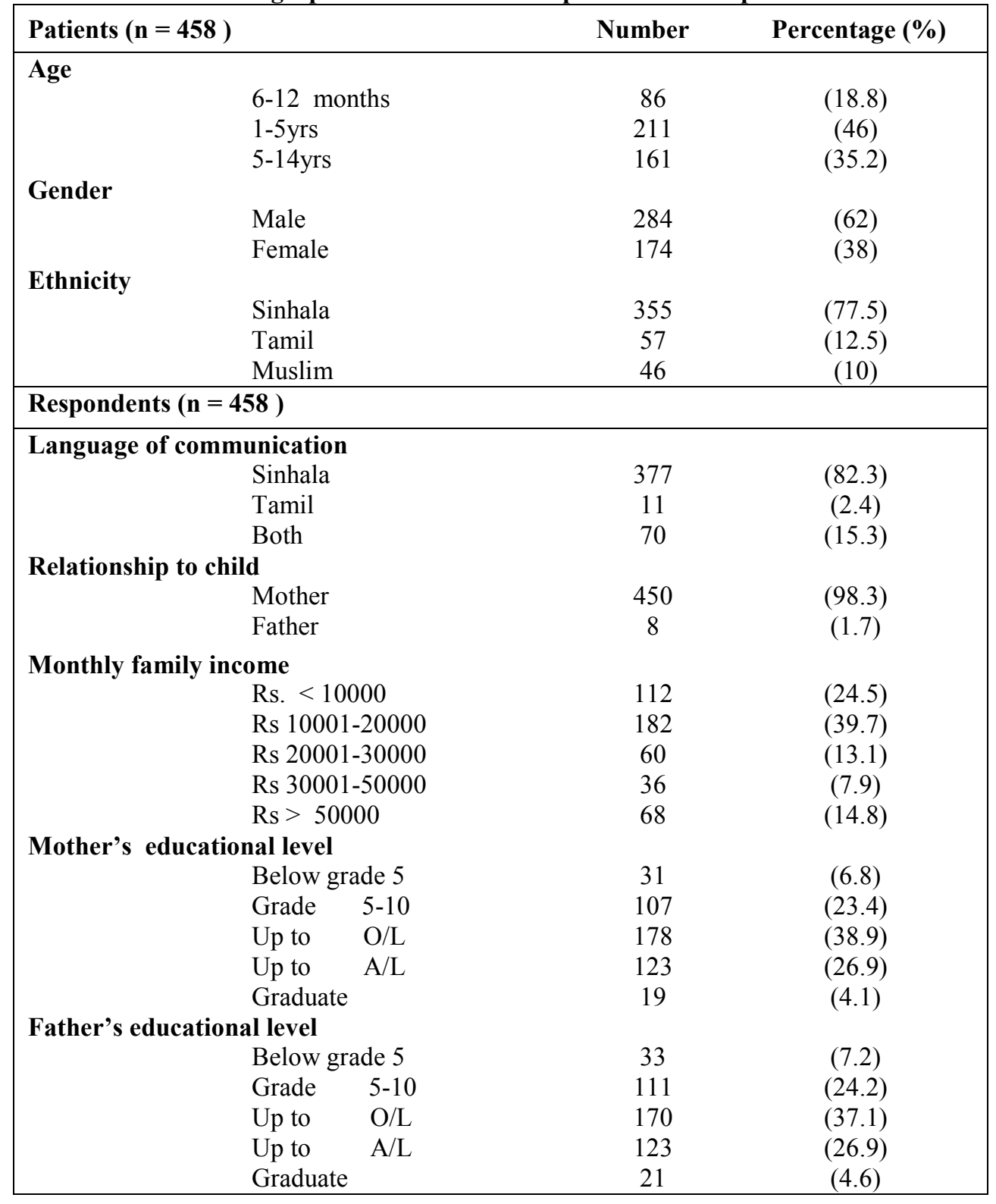

Parental satisfaction and knowledge of illness are shown in table 2 ,

All three categories of health care personnel were rated "good" or above for "establishing rapport at initial encounter", with mean scores 7.52 (doctors), 6.77 (nurses) and 7.22 (physiotherapists). With regard to initial patient-provider interaction $71.8 \%$ of doctors were rated "very good" or "excellent" while only $41.1 \%$ of nurses and $57.2 \%$ of physiotherapists achieved similar ratings, indicating that doctors were the best at this aspect of communication. However, $2.6 \%$ doctors, $3.9 \%$ of nurses and $2 \%$ of physiotherapists were rated "poor" or "very poor" in establishing rapport. Mean scores for "listened adequately to patient/ parent" were similar and doctors scored a mean of 7.5. There was a lower level of satisfaction for "adequate time given for questioning" with mean score of 6.9 , and only $52.6 \%$ of doctors described as "very good" or "excellent"; and $5.5 \%$ were rated "poor". (Table 2)

Satisfaction regarding doctor's "explanations on child's disease process" and "treatment options" showed "poor" ratings in $6.3 \%$ and $3.9 \%$ of doctors respectively. There was dissatisfaction ("poor" or "very poor") on communication regarding "prognosis" by $100(21.8 \%)$ and on "follow up plans and future management" by 93 (20.3\%). (Table 2 ) 
Table 2: Parental satisfaction and knowledge of illness

\begin{tabular}{|c|c|c|c|c|c|}
\hline \multicolumn{6}{|c|}{ Satisfaction on parent - provider interaction at first meeting (initial rapport) } \\
\hline & Very poor & Poor & Good & Very good & Excellent \\
\hline $\begin{array}{l}\text { Doctors }(\mathbf{n}=\mathbf{4 5 8}) \\
\text { Initial rapport } \\
\text { Listened adequately } \\
\text { Gave enough time for questions }\end{array}$ & $\begin{array}{c}1(0.2 \%) \\
0 \\
0\end{array}$ & $\begin{array}{l}11(2.4 \%) \\
9(2 \%) \\
25(5.5 \%)\end{array}$ & $\begin{array}{l}117(25.5 \%) \\
116(25.3 \%) \\
192(41.9 \%)\end{array}$ & $\begin{array}{l}305(66.6 \%) \\
312(68.1 \%) \\
233(50.9 \%)\end{array}$ & $\begin{array}{c}24(5.2 \%) \\
21(4.6 \%) \\
8(1.7 \%)\end{array}$ \\
\hline $\begin{array}{l}\text { Nurses }(n=458) \\
\text { Initial meeting }\end{array}$ & 0 & $18(3.9 \%)$ & $250(54.6 \%)$ & $185(40.4 \%)$ & $5(1.1 \%)$ \\
\hline $\begin{array}{l}\text { Physiotherapist }(n=49) \\
\text { Initial meeting }\end{array}$ & 0 & $1(2 \%)$ & $20(40.8 \%)$ & $26(53.1 \%)$ & $2(4.1 \%)$ \\
\hline \multicolumn{6}{|c|}{ Satisfaction on verbal interaction when delivering in-door care } \\
\hline $\begin{array}{l}\text { Doctors } \\
\text { Explanation regarding } \\
\text { Treatment options } \\
\text { Disease } \\
\text { Prognosis } \\
\text { Follow up } \\
\end{array}$ & $\begin{array}{c}0 \\
1(0.2 \%) \\
1(0.2 \%) \\
1(0.2 \%)\end{array}$ & $\begin{array}{l}18(3.9 \%) \\
28(6.1 \%) \\
99(21.6 \%) \\
92(20.1 \%) \\
\end{array}$ & $\begin{array}{c}189(41.3 \%) \\
205(44.8 \%) \\
311(67.8 \%) \\
316(69 \%) \\
\end{array}$ & $\begin{array}{c}241(52.6 \%) \\
219(47 \%) \\
46(10 \%) \\
48(10.5 \%) \\
\end{array}$ & $\begin{array}{l}10(2.2 \%) \\
5(1.1 \%) \\
1(0.2 \%) \\
1(0.2 \%) \\
\end{array}$ \\
\hline $\begin{array}{l}\text { Nurses } \\
\text { Explanation regarding } \\
\text { Nursing procedures }\end{array}$ & 0 & $21(4.6 \%)$ & $236(51.5 \%)$ & $198(43.2 \%)$ & $3(0.7 \%)$ \\
\hline $\begin{array}{l}\text { Physiotherapist } \\
\text { Explanation regarding } \\
\text { Physio. technique/s } \\
\end{array}$ & 0 & $1(2 \%)$ & $12(24.5 \%)$ & $35(71.4 \%)$ & $1(2 \%)$ \\
\hline \multicolumn{6}{|c|}{ Satisfaction on overall attitude to patients in three categories of hospital staff } \\
\hline $\begin{array}{l}\text { Doctors } \\
\text { Kind, Friendly, Respectful } \\
\text { Provided privacy }\end{array}$ & $\begin{array}{l}0 \\
0\end{array}$ & $\begin{array}{l}10(2.2 \%) \\
11(2.4 \%)\end{array}$ & $\begin{array}{l}128(27.9 \%) \\
130(28.4 \%)\end{array}$ & $\begin{array}{l}312(68.2 \%) \\
311(67.9 \%)\end{array}$ & $\begin{array}{l}8(1.7 \%) \\
6(1.3 \%)\end{array}$ \\
\hline $\begin{array}{l}\text { Nurses } \\
\text { Kind, Friendly, Respectful } \\
\text { Provided privacy }\end{array}$ & $\begin{array}{l}0 \\
0\end{array}$ & $\begin{array}{c}24(5.2 \%) \\
23(5 \%)\end{array}$ & $\begin{array}{l}219(47.8 \%) \\
218(47.6 \%) \\
\end{array}$ & $\begin{array}{l}212(46.3 \%) \\
214(46.7 \%) \\
\end{array}$ & $\begin{array}{l}3(0.7 \%) \\
3(0.7 \%)\end{array}$ \\
\hline $\begin{array}{l}\text { Physiotherapist } \\
\text { Kind, Friendly, Respectful } \\
\text { Provided privacy }\end{array}$ & $\begin{array}{l}0 \\
0\end{array}$ & $\begin{array}{l}0 \\
0\end{array}$ & $\begin{array}{l}11(22.4 \%) \\
11(22.4 \%)\end{array}$ & $\begin{array}{l}38(77.6 \%) \\
38(77.6 \%)\end{array}$ & $\begin{array}{l}0 \\
0\end{array}$ \\
\hline \multicolumn{6}{|c|}{ Satisfaction with psychological support provided by health care personnel } \\
\hline $\begin{array}{l}\text { Doctors } \\
\text { Nurses } \\
\text { Physiotherapists } \\
\end{array}$ & $\begin{array}{c}1(0.2 \%) \\
0 \\
0 \\
\end{array}$ & $\begin{array}{l}127(27.7 \%) \\
88(19.2 \%) \\
9(18.36 \%) \\
\end{array}$ & $\begin{array}{l}287(62.7 \%) \\
305(66.6 \%) \\
34(69.38 \%) \\
\end{array}$ & $\begin{array}{c}39(8.5 \%) \\
63(13.8 \%) \\
6 \\
\end{array}$ & $\begin{array}{l}4(0.9 \%) \\
2(0.4 \%) \\
0\end{array}$ \\
\hline \multicolumn{6}{|c|}{ Parental knowledge about child's illness } \\
\hline Disease & $1(0.2 \%)$ & $25(5.5 \%)$ & $201(43.8 \%)$ & $228(49.8 \%)$ & $3(0.7 \%)$ \\
\hline Follow up & $1(0.2 \%)$ & $75(16.4 \%)$ & $308(67.2 \%)$ & $71(15.5 \%)$ & $3(0.7 \%)$ \\
\hline Home management & $2(0.4 \%)$ & $79(17.2 \%)$ & $300(65.5 \%)$ & $75(16.4 \%)$ & $2(0.4 \%)$ \\
\hline Future/ prognosis & $1(0.2 \%)$ & $94(20.5 \%)$ & $301(65.7 \%)$ & $60(13.1 \%)$ & $2(0.4 \%)$ \\
\hline
\end{tabular}

Satisfaction with nurses "explanation about the nursing procedure/s" was "very good" or "excellent" in only $43.9 \%$ and $4.6 \%$ said this was "poor", whereas explanations by the physiotherapists met with greater satisfaction - with "good" and "very good" in $24.5 \%$ and $71.4 \%$ but $2 \%$ said this aspect was "poor" but none said it was "very poor".

Approximately $95 \%$ of parents thought that all 3 categories of health care workers were kind, friendly and respectful and provided for parent's / patients' privacy. However, $5.2 \%$ of nurses and $2.2 \%$ of doctors scored as "poor" in this aspect. None of the physiotherapists were rated "poor" on such attributes. They were all being rated "good" $(22.4 \%)$ or "very good" (77.6\%). (Table 2)

Mean satisfaction scores according to clinical and demographic characteristics are shown in table 3. 
Table 3

Mean satisfaction scores according to clinical and demographic characteristics

\begin{tabular}{|l|c|c|}
\hline & Acute illness & Chronic illness \\
\hline Initial rapport & & 7.52 \\
Doctor & 7.46 & 6.77 \\
Nurse & 6.77 & 7.22 \\
Physiotherapist & 7.11 & 7.40 \\
\hline Attitude & & 6.83 \\
Doctor & 7.41 & 7.54 \\
Nurse & 6.87 & 5.66 \\
Physiotherapist & 7.55 & 5.89 \\
\hline Moral/psychological support & & 5.93 \\
Doctor & 5.63 & 5 \\
Nurse & 5.91 & 5.77 \\
Physiotherapist & & \\
\hline
\end{tabular}

Parents were dissatisfied with "psychological / moral support provided" by all three categories. Mean score for doctors was 5.66, nurses 5.89 and physiotherapists 5.93. (Table 3)

Ratings of "poor' and 'very poor' were obtained by $27.7 \%$ doctors, $19.2 \%$ nurses and $18.36 \%$ physiotherapists (Table 2). Number of parents who had an adequate knowledge about their child's disease was $430(94 \%)$ but $20 \%$ did not have a clear idea of disease prognosis, and subsequent management. (Table 2)

Demographic and patient characteristics such as ethnicity, patient's gender or the duration of illness (i.e. acute/ short lasting vs. chronic/ long standing) had not affected the satisfaction scores to a statistically significant degree. (Table 4)

Table 4

Significance of Patient Satisfaction Scores in relation to demographic and clinical variables

\begin{tabular}{|l|c|c|c|}
\hline & $\begin{array}{c}\text { Gender } \\
\text { (P value) }\end{array}$ & $\begin{array}{c}\text { Ethnicity } \\
\text { (P value) }\end{array}$ & $\begin{array}{c}\text { Length of the illness } \\
\text { (P value) }\end{array}$ \\
\hline & & & 0.259 \\
Doctor & 0.338 & 0.970 & 0.580 \\
Nurse & 0.480 & 0.920 & 0.748 \\
Physiotherapist & 0.385 & 0.135 & \\
\hline
\end{tabular}

\section{Discussion}

Studies done on the quality of health care are limited in Sri Lanka and a previous qualitative study on client satisfaction in a single paediatric ward at LRH in 1996 did not evaluate different categories of health care personnel ${ }^{4}$. Despite criticism on communication skills of health care personnel in hospital settings in Sri Lanka, we found the overall satisfaction among parents at LRH to be high and similar to patientphysician communication in developed countries ${ }^{3,5}$.

Doctors were rated highest for their ability to establish rapport at initial encounter. However lower ratings were awarded for their ability to inform parents of prognosis and for discussion of follow-up management plans, demonstrating dissatisfaction with communication during hospital stay. Time given by doctors for questions of parents and advice given about the illness were also considered inadequate and are areas that need improvement.

There was overall satisfaction regarding a caring attitude by all three categories of personnel with physiotherapists rated best in this aspect, doctors next and nurses the lowest. The high ratings of physiotherapists may be due to the time spent in providing care because of mutual understanding between parents and provider and are positively corelated with the length of consultation ${ }^{6,7}$.

There was no significant difference in the demographic variables of ethnicity or gender and communication received. Comparable or even higher satisfaction scores in chronic illness are not in keeping with findings elsewhere ${ }^{8}$. However, our study did not show a statistical difference between satisfaction levels for acute and chronic conditions. 
We concluded that although overall satisfaction was good, some aspects need improving by all three categories of health care personnel. Providing psychological support, more explanation of disease, prognosis and subsequent care and giving opportunity to parents to ask questions were the main deficient areas.

The findings in a large tertiary children's hospital may not reflect satisfaction levels with paediatric services in other hospitals in the country. Further, the high parental expectations at LRH due to it being the premier children's hospital may have resulted in greater difficulties in achieving higher satisfaction scores.

\section{Acknowledgements}

We thank Dr Dilini Vipulaguna, Dr Madara Jayasekara and Dr Gangani Attanapola Research Assistants, Dept. of Paediatrics, Faculty of Medicine, Colombo for assistance with data processing.

\section{References}

1. Ravi P. Rannan-Eliya, Lankani S. Sri Lanka:"Good Practice" in expanding health care coverage. Research Studies Series 3. Institute for health policy. 2009.

2. Annual Health Bulletin, Ministry of Health, Sri Lanka. 2007; 31-3
3. Francis V, Barbara M. Korsch, Marie , Morris, Gaps in doctor-patient communication Patients' Response to Medical Advice. New England Journal of Medicine. 1969; 280:535-40. http://dx.doi.org/10.1056/NEJM196903062801004

4. De Silva KSH, Dharmage SC. Assessment of client satisfaction in a paediatric ward Ceylon Medical Journal.1996; 41: 148-50.

5. Symone BD, Martin JM, Jan HS, Lidwina DVW. Health-related quality-of-life assessments and patient-physician communication. The Journal of the American Medical Association 2002; 288(23): 3027-34. http://dx.doi.org/10.1056/NEJM196903062801004

6. Hart C, Kelleher K,Drotor D, Scholle S. Parentprovider communication and parental satisfaction with care of children with psychological problems. Patient Education and Counseling 2007; 68:179-85.

http://dx.doi.org/10.1016/j.pec.2007.06.003

7. Halfon $\mathrm{N}$, Inkelas $\mathrm{M}$, Mistry $\mathrm{R}$, Olson LM. Satisfaction with health care for young children. Pediatrics 2004; 113: 98.

8. Gregory S, Liptak MD, Jacalyn T, Yingling MS et al .Satisfaction with primary health care received by families of children with developmental disabilities. Journal of Pediatric Health Care. 2006; 20(4): 245-52. http://dx.doi.org/10.1016/j.pedhc.2005.12.008 